\title{
Pregnancy in European bison (Bison bonaus) with generalized tuberculosis - no evidence of vertical transmission
}

\author{
Anna Didkowska ${ }^{1, A-D, F \oplus}$, Blanka Orłowska ${ }^{1, A, F}{ }^{\oplus}$, Monika Krajewska-Wędzina ${ }^{2, A-B, F \oplus}$,

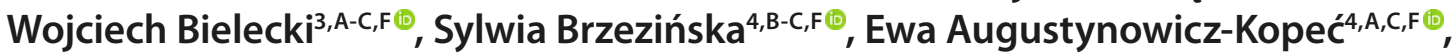 \\ Wanda Olech ${ }^{5, \mathrm{~A}, \mathrm{E}-\mathrm{F} \oplus}{ }^{\oplus}$, Krzysztof Anusz ${ }^{1, A, C, E-F \oplus}$ \\ ${ }^{1}$ Department of Food Hygiene and Public Health Protection, Institute of Veterinary Medicine, University of Life Sciences \\ (SGGW), Warsaw, Poland \\ 2 Department of Microbiology, National Veterinary Research Institute, Puławy, Poland \\ ${ }^{3}$ Department of Pathology and Veterinary Diagnostics, Institute of Veterinary Medicine, University of Life Sciences \\ (SGGW), Warsaw, Poland \\ ${ }^{4}$ Department of Microbiology, National Tuberculosis Reference Laboratory, National Tuberculosis and Lung Diseases \\ Research Institute, Warsaw, Poland \\ ${ }^{5}$ Institute of Animal Sciences, University of Life Sciences (SGGW), Warsaw, Poland \\ A - Research concept and design, B - Collection and/or assembly of data, C - Data analysis and interpretation, \\ $D$ - Writing the article, E-Critical revision of the article, F - Final approval of the article
}

\begin{abstract}
Didkowska A, Orłowska B, Krajewska-Wędzina M, Bielecki W, Brzezińska S, Augustynowicz-Kopeć E, Olech W, Anusz K. Pregnancy in European bison (Bison bonaus) with generalized tuberculosis - no evidence of vertical transmission. Ann Agric Environ Med. $2022 ; 29(2)$ : $300-302$. doi: $10.26444 /$ aaem/141612
\end{abstract}

\section{Abstract}

Introduction and objective. One of the main health threats to the endangered European bison (Bison bonsasus) is bovine tuberculosis, the pathogenesis of which in this species is not fully known. The aim of the study was to confirm a possible case of vertical transmission from a pregnant European bison with generalized tuberculosis to its 12-week-old foetus.

Materials and method. During the autopsy it was found that the bison had become pregnant, despite an advanced stage of tuberculosis. Material collected from the organs and foetus was placed on Lowenstein and Stonebrink media and incubated at $37^{\circ} \mathrm{C}$ for 12 weeks.

Results. Mycobacteria were isolated from the lungs and lymph nodes; however, the tissue of the foetus and fragments of the reproductive system were negative.

Conclusion. Vertical transmission was excluded, although it cannot be ruled out that infection could occur as pregnancy progresses.

\section{Tey words}

pregnancy, intrauterine infection, foetus, bovine tuberculosis, Mycobacterium caprae, European bison

\section{INTRODUCTION}

The European bison (Bison bonasus) is a protected species, and due to difficulties in population management [1], and in the face of numerous environmental $[2,3]$ and health threats [4-7], it requires active protection [8]. Bovine tuberculosis (BTB) has proven to be one of the most dangerous diseases facing the European bison in recent decades [9] and one that poses a threat to the restitution of the species. While BTB is caused by both Mycobacterium bovis and Mycobacterium caprae belonging to the MTBC (Mycobacterium tuberculosis complex), the latter species has been predominantly isolated from European bison in Poland [10]. BTB is an infectious, debilitating disease, as well as a dangerous zoonosis. In European bison, due to the close phylogenetic relationship with cattle, knowledge about the sources, transmission and pathogenesis of BTB is often derived from observations on cows. Each case of natural infection in European bison

Address for correspondence: Anna Didkowska, Department of Food Hygiene and Public Health Protection, Institute of Veterinary Medicine, University of Life Sciences (SGGW), Nowoursynowska 166, 02-787, Warsaw, Poland

E-mail: anna_didkowska@sggw.edu.pl

Received: 05.07.2021; accepted: 26.08.2021; first published: 22.09.2021 presents a unique opportunity for study, which so far has generally been restricted to serological sampling [11].

\section{OBJECTIVE}

The aim of the study was to present the case of pregnancy in European bison naturally infected with $M$. caprae, with generalized tuberculosis, and to confirm possible intrauterine transmission.

\section{MATERIALS AND METHOD}

The 10-year-old European female bison described in the present study came from a herd in which BTB had been repeatedly confirmed in subsequent individuals since 2013 by the Smardzewice Bison Centre, located in central Poland, in the Łódź Province, Tomaszów County, in the Smardzewice Forest District. The diagnosis was based on a positive gammainterferon test result in 2017 [12]) and a positive M. caprae culture result from the material collected ante-mortem [13]. Two days before euthanasia, a simplified clinical examination 
was conducted from a distance of about two meters. Rapid breathing and shortness of breath, indicative of dyspnea, were observed. No other symptoms had been previously reported by the animal keepers; however, this may have been due to the environmental conditions: it would have been difficult to notice any fatigue, weakness, hunger or thirst characteristic of BTB in the studied animal as it was supplied with food and water. In natural conditions, European bison habitually walk several kilometers a day in search of food and drinking water [14]. So far, clinical symptoms of BTB (coughing, purulent discharge from the nose, diarrhea and weight loss) have only been described once in European bison [15].

Due to the BTB-positive ante-mortem results, the European bison female was euthanized in accordance with the decision of The Polish Ministry of the Environment (No. DOP-WPN.286.219.2018.MS).

Tissue samples of the lymph nodes, lungs, as well as the entire foetus, uterus and ovaries were collected for microbiological studies. The culture was conducted as described by Krajewska-Wędzina et al. [16] has proved to be more accurate in European bison than direct MTBC DNA detection [12]. If colonies appeared on the media, their DNA was isolated using Genolyse Isolatin Kit (Hain Lifescience, Germany) and the mycobacteria species were differentiated using GenoType ${ }^{\varpi}$ MTBC assay (Hain Lifescience, Germany) as described previously [9].

\section{RESULTS}

Necropsy revealed extensive tuberculous gross lesions in the lungs and lymph nodes (Fig. 1), as well as serosal tubercles on the peritoneum. During the autopsy, the cow was found to be pregnant (Fig. 2). Foetal age was assessed to be about 12 weeks.

Mycobacteria were isolated from lung and lymph node material and identified as M. caprae according to Didkowska et al. [11]. No mycobacteria were isolated from the uterine, ovarian or foetal specimens.

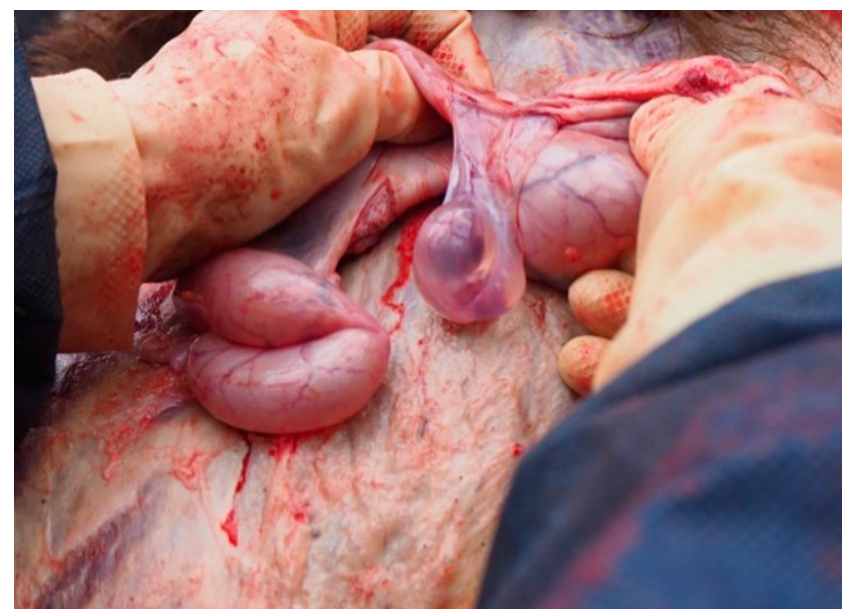

Figure 2. European bison foetus visible during autopsy

\section{DISSCUSION}

Despite the very advanced stage of disease, the study revealed no vertical transmission into the foetus, nor any mycobacteria in the maternal reproductive system. However, it cannot be ruled out that an intrauterine infection could have occurred as the pregnancy progressed. Some cases of infection with bovine mycobacterium in the womb or during birth have been noted in cattle, but these cases are sporadic [17]. It is possible that congenital tuberculosis may occur following the involvement of the genital tract or placenta; in such cases, infection may spread via the umbilical veins or amniotic fluid [18]. However, in cattle, the most common route of Mycobacterium spp. infection remains the aerogenic route, followed by the alimentary route [19], and it can be assumed that this would also be the case in European bison, with a similar frequency.

It should be emphasized that the fact that she became pregnant and maintained the foetus indicates that the studied European bison was otherwise in relatively good

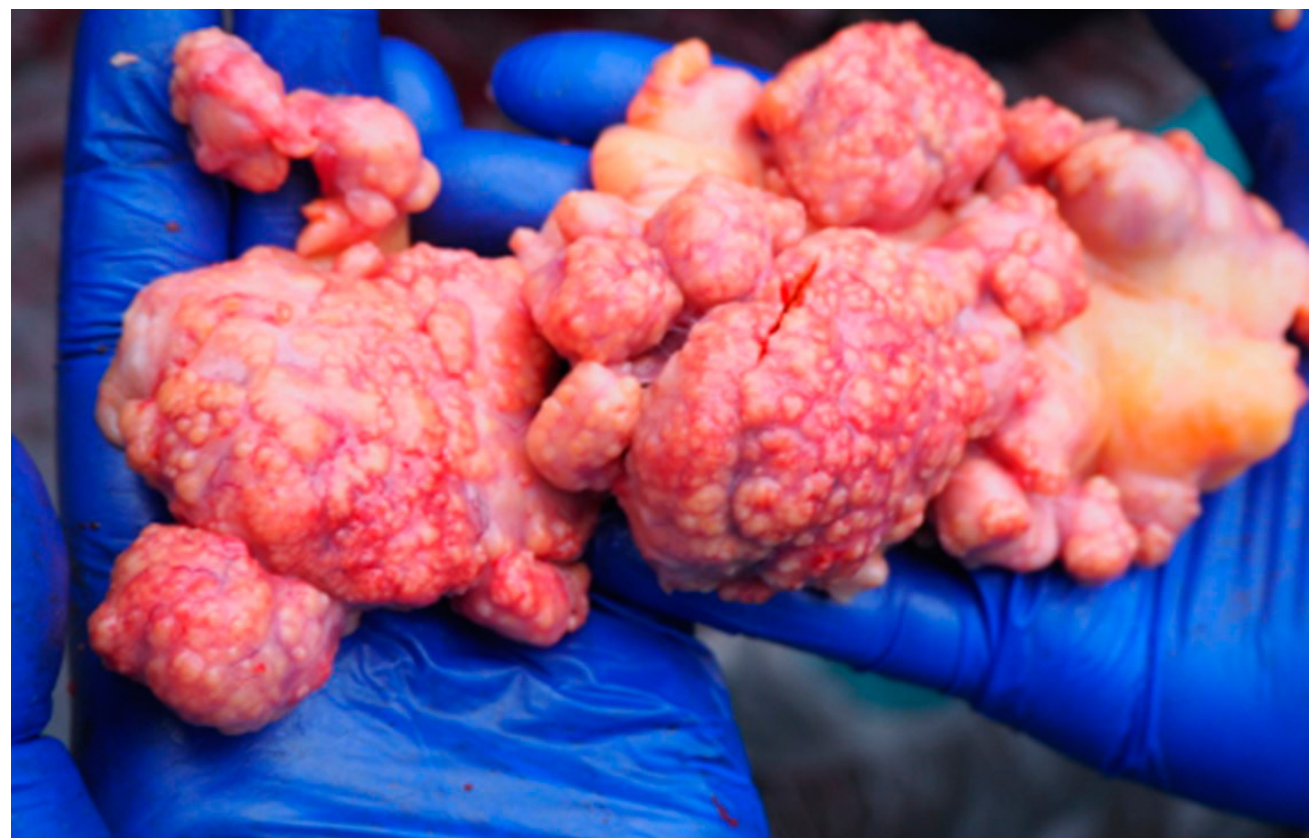

Figure 1. Tuberculous granulomas forming conglomerates 
condition. Such cases have been described before in humans [20]. It should be noted that tuberculosis was considered to follow a more aggressive course during pregnancy [21].

To the best of the authors' knowledge, the youngest MTBCpositive European bison identified so far was a 6 -year-old cow [12]. However, not all cases, especially those from the Bieszczady Mountains, have been thoroughly documented in the literature, so it should not be ruled out that mycobacterial infection may also have been present in younger animals of this species.

The fact that the placenta and amniotic fluid were not included in the present study may be considered a limitation. However, we deliberately chose to focus on the foetal tissues because tuberculous placentitis does not always lead to congenital infection [22]. Additionally we have found the organs of the cow reproductive system to be MTBC negative.

A key value of the present study is the fact that tuberculosis in bison in Poland is a current problem, and has been observed in many locations around the country, including a farm in Bukowiec, Kujawska-Pomorski Province, northeast Poland [23], in free-living herds in Bieszczady, SubCarpathian Province of southeast Poland [24], in Warsaw zoo [25], in the closed breeding center in Smardzewice [8], and also in the 'Wolisko' homestead in the Borecka Forest, Warmian-Mazurian Province, northeast Poland [25]. Hence, tuberculosis remains a serious problem for the endangered European bison, and there is a pressing need to learn about its pathogenesis to allow better monitoring and disease control.

\section{CONCLUSIONS}

An individual with such advanced tuberculous gross lesions becoming pregnant may be considered a rare phenomenon. In addition, no vertical transmission of mycobacteria was found, despite generalized tuberculosis. However, further studies are needed to confirm this, as it is extremely difficult to conduct such research under natural conditions, which further emphasizes the uniqueness and value of the present research. It is therefore planned to take such action in any further cases requiring the elimination of a BTB-positive pregnant female European bison.

\section{REFERENCES}

1. Klich D, Łopucki R, Perlińska-Teresiak M, et al. Human-Wildlife Conflict: The Human Dimension of European Bison Conservation in the Bieszczady Mountains (Poland). Animals. 2021; 11(2): 503.

2. Klich D, Kitowski I, Łopucki R, et al. Essential differences in the mineral status of free-ranging European bison Bison bonasus populations in Poland: The effect of the anthroposphere and lithosphere. Sci Total Environ. 2021; 757: 143926.

3. Pyziel AM, Demiaszkiewicz AW. Coccidia (Apicomplexa: Eimeriidae) of the lowland European bison (Bison bonasus bonasus L.) in Poland. Vet Parasitol. 2014; 202: 138-144.

4. Krzysiak MK, Jabłoński A, Iwaniak W, et al. Seroprevalence and risk factors for selected respiratory and reproductive tract pathogen exposure in European bison (Bison bonasus) in Poland. Vet Microbiol. 2018; 215: 57-65.
5. Demiaszkiewicz AW, Pyziel AM, Lachowicz J, et al. Occurrence of tapeworms Moniezia benedeni (Moniez, 1879) in European bison Bison bonasus L. in Białowieża Primeval Forest. Ann Parasitol. 2020; 66(1): 107-109.

6. Kwiecień E, Stefańska I, Chrobak-Chmiel D, et al. Trueperella pyogenes isolates from livestock and European bison (Bison bonasus) as a reservoir of tetracycline resistance determinants. Antibiotics 2021; 10(4): 380 .

7. Olech W, Klich D, Perzanowski K. Development of a new action plan for the European bison. Oryx 2019; 53: 214-214.

8. Didkowska A, Orłowska B, Krajewska-Wędzina $M$, et al. Microbiological and molecular monitoring for bovine tuberculosis in the Polish population of European bison (Bison bonasus). https://doi. org/10.26444/aaem/130822

9. Didkowska A, Krajewska-Wędzina M, Orłowska B, et al. Molecular Characterization of Mycobacterium spp. Isolated from Cattle and Wildlife in Poland. doi: 10.5772/intechopen.96695. In: Molecular Epidemiology Study of Mycobacterium Tuberculosis Complex [Working Title], IntechOpen, London, UK.

10. Didkowska A, Orłowska B, Witkowski L, et al. Biopsy and tracheobronchial aspirates as additional tools for the diagnosis of bovine tuberculosis in living European bison (Bison bonasus). Animals. 2020: 10; 2017. doi: 10.3390/ani10112017

11. Didkowska A, Krajewska-Wędzina M, Bielecki W, et al. Antibody responses in European bison (Bison bonasus) naturally infected with Mycobacterium caprae. Vet Microbiol. 2021; 253: 108952.

12. Didkowska A. Improved algorithm for clinical and laboratory diagnostics of bovine tuberculosis in European bison (Bison bonasus). PhD Thesis. Warsaw: University of Life Sciences; 2020.

13. Krasińska M, Krasiński Z. Żubr, monografia przyrodnicza. Kielce: Drukarnia im. A. Półtawskiego; 2017.

14. Zimpel CK, Brum JS, de Souza Filho AF, et al. Mycobacterium bovis in a European bison (Bison bonasus) raises concerns about tuberculosis in Brazilian captive wildlife populations: a case report. BMC Res Notes. 2017. doi: 10.1186/s13104-017-2413-3

15. Krajewska-Wędzina M, Didkowska A, Sridhara AA, et al. Transboundary tuberculosis: Importation of alpacas infected with Mycobacterium bovis from the United Kingdom to Poland and potential for serodiagnostic assays in detecting tuberculin skin test false-negative animals. Transbound Emerg Dis. 2020; 67(3): 1306-1314.

16. Neill SD, Pollock JM, Bryson DB, et al. Pathogenesis of Mycobacterium bovis infection in cattle. Vet Microbiol. 1994; 40: 41-52.

17. Ozyigit MO, Senturk S, Akkoc A. Suspected congenital generalised tuberculosis in a newborn calf. Vet Rec. 2007; 160(9): 307-8.

18. Stahelin-Massik J, Carrel T, Duppenthaler A, et al. Congenital tuberculosis in a premature infant. Swiss Med Wkly. 2002; 132: 598-602.

19. Pollock JM, Neill SD. Mycobacterium bovis infection and tuberculosis in cattle. Vet J. 2002; 163: 115-127.

20. Smith KC. Congenital tuberculosis: a rare manifestation of a common infection. Curr Opin Infect. 2002; 15(3): 269-74.

21. Keskin N, Yilmaz S. Pregnancy and tuberculosis: to assess tuberculosis cases in pregnancy in a developing region retrospectively and two case reports. Arch Gynecol Obstet. 2008; 278(5): 451-5.

22. Michaels MG, Sanchez P, Ling Lin P. Congenital Toxoplasmosis, Syphilis, Malaria, and Tuberculosis. Editor(s): Christine A. Gleason, Sandra E. Juul, Avery's Diseases of the Newborn (Tenth Edition), Elsevier, 2018. pages 527-552.e6, https://doi.org/10.1016/B978-0-32340139-5.00038-3

23. Anusz K, Orłowska B, Krajewska-Wędzina M, et al. Ante-mortem and post-mortem tuberculosis diagnostics in three European Bison (Bison bonasus caucasicus) from the enclosure in Bukowiec in the Bieszczady National Park in Poland. Med Wet. 2017; 73: 642-646.

24. Krajewska M, Zabost A, Welz M, et al. Transmission of Mycobacterium caprae in a herd of European bison in the Bieszczady Mountains, Southern Poland. Eur J Wildl Res. 2015; 61: 429-33.

25. Krajewska M, Kozińska M, Orłowska B, et al. Molecular analysis methods in epidemiological investigations of animal tuberculosis in European bison. European Bison Conservation Newsletter 2015; 8: 79-86. 